\title{
Opponensplasty hypothenar muscles transfer
}

\author{
Fuad Hashem MBBS FRCSC, Miroslaw Stranc FRCS(ENG) FRCSC FACS \\ Section of Plastic Surgery, University of Manitoba, Winnipeg, Manitoba
}

\begin{abstract}
F Hashem, M Stranc. Opponensplasty hypothenar muscles transfer. Can J Plast Surg 1993;1(1):36-38. Opponensplasty using hypothenar muscles (abductor and flexor digiti minimi) is presented. This technique was used with gratifying results in two patients; the first having sustained congenital absence of the thenar eminence and the second presenting with a traumatic loss of the thenar muscles. Function 10 years after treatment is described for the later and one year follow-up for the former.
\end{abstract}

Key Words: Hypothenar muscles, Opponensplasty

\section{Transfert des muscles de l'éminence hypothénar par opponenplastie}

RÉSUMÉ: On présente ici une technique d'opponenplastie appliqués aux muscles de l'éminence hypothénar (abducteur et fléchisseur des auriculaires). Cette technique a été utilisée avec des résultats satisfaisants chez deux patients: le premier présentant une absence congénitale de l'éminence thénar et le second présentant une perte traumatique des muscles thénars. La fonction dix ans après le traitement du dernier est décrite, ainsi que le suivi d'un an effectué chez le premier.

$\mathrm{T}$ he thumb is unique in function; because of its position and movement it cooperates with all other digits (1). This is largely brought about by muscles of the thenar eminence (2). Loss of these muscles leads to significant functional impairment of the hand.

There have been many surgical techniques described to restore the opposition of the thumb (3-10). The most popular uses the transfer of long tendons of various types, ignoring one of the basic principles of plastic surgery - 'replace like with like'.

In 1921, Huber (11) and Nicolaysen (12) independently used the abductor digiti minimi transfer to restore thumb opposition. We felt that this approach was appropriate in selected cases and are reporting both the technique and the functional evaluation in two patients who had transfer of the hypothenar muscles.

\section{TECHNIQUE AND PATIENTS}

Case 1

An 18-old-male, left hand dominant, with right congenital absence of thenar muscles, complained of difficulty in using his right hand for picking up small objects. On examination

Correspondence and reprints: Dr MF Stranc, Manitoba Clinic, 790 Sherbrook Street, Winnipeg, Manitoba R3A IM3. Telephone (204) 774-6541, Fax (204) 783-7163

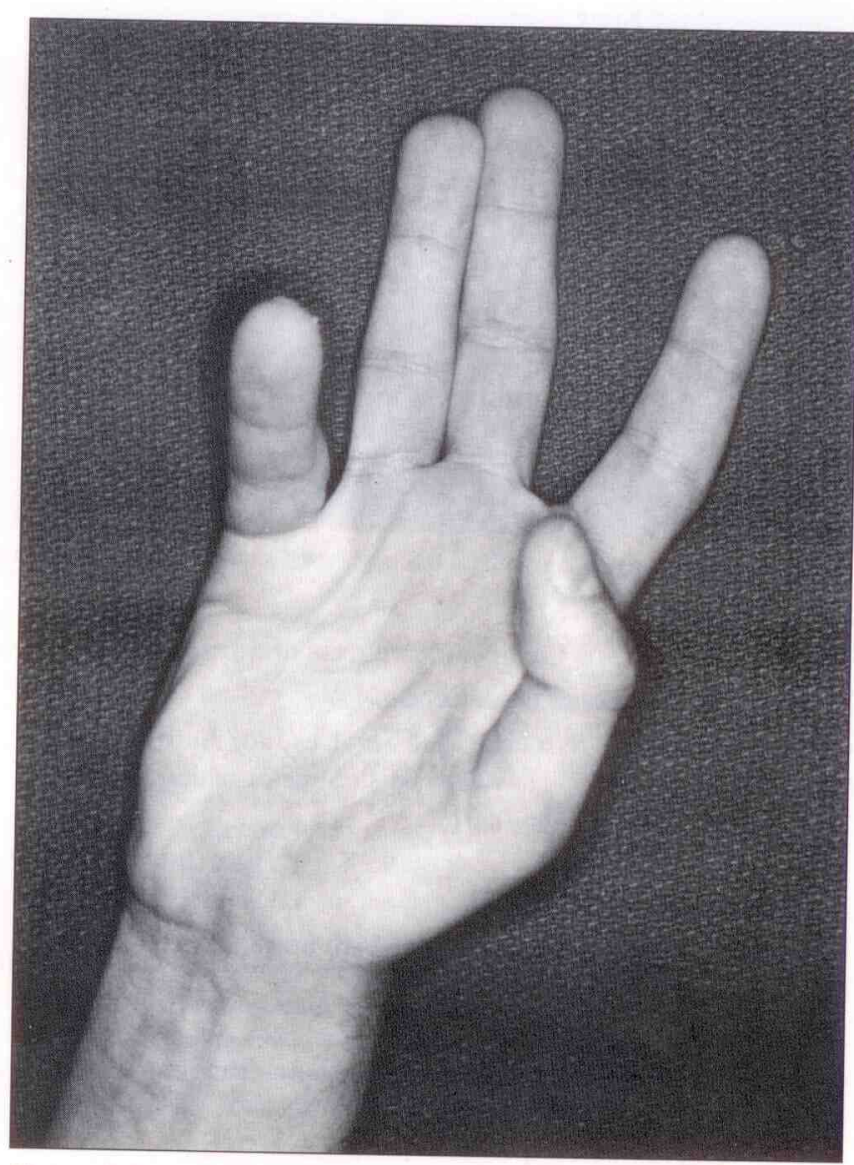

Figure 1) Case 1: Marked thenar wasting and inability to oppose thumb 
TABLE 1: Functional evaluation

\begin{tabular}{lll}
\hline Evaluation & Case 1 & Case 2 \\
\hline $\begin{array}{l}\text { Patient opinion } \\
\text { Performance of daily task }\end{array}$ & $\begin{array}{l}\text { Excellent } \\
\text { Good }\end{array}$ & $\begin{array}{l}\text { Good } \\
\text { Good }\end{array}$ \\
$\begin{array}{l}\text { Appearance } \\
\text { Evaluation of pinch }\end{array}$ & $\begin{array}{c}\text { Excellent } \\
\text { Fair }\end{array}$ \\
$\begin{array}{l}\text { Good } \\
\text { Range of motion compared to } \\
\text { Other side }\end{array}$ & $90 \%$ & $71 \%$ \\
Strength compared to other side & & \\
$\quad$ Opposition & $29 \%$ & $32 \%$ \\
Grip & $82 \%$ & $72 \%$ \\
$\quad$ Tripod & $30 \%$ & $39 \%$ \\
$\quad$ Key pinch & $86 \%$ & $58 \%$ \\
Little finger flexion & $61 \%$ & $90 \%$ \\
\hline
\end{tabular}

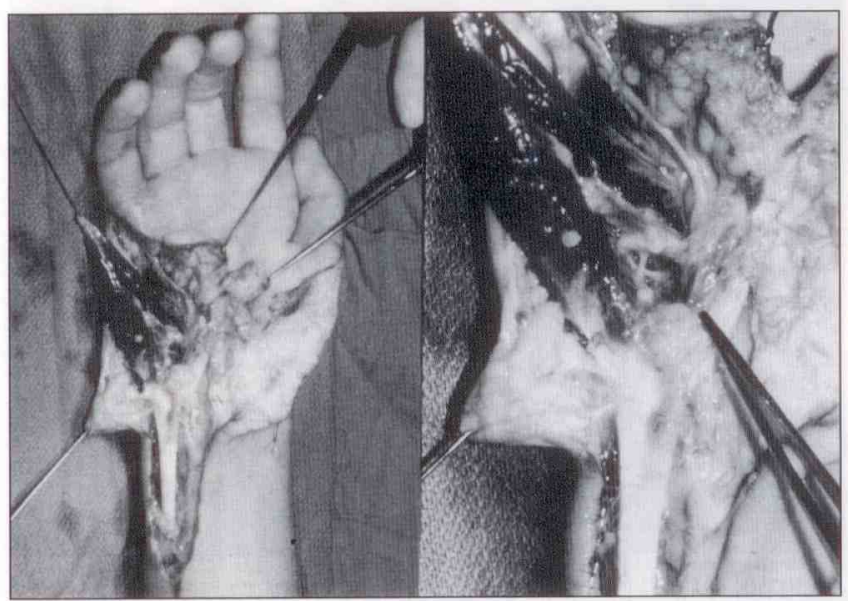

Figure 2) Case 1: Abductor and flexor digiti minimi dissected preserving the neurovascular bundle

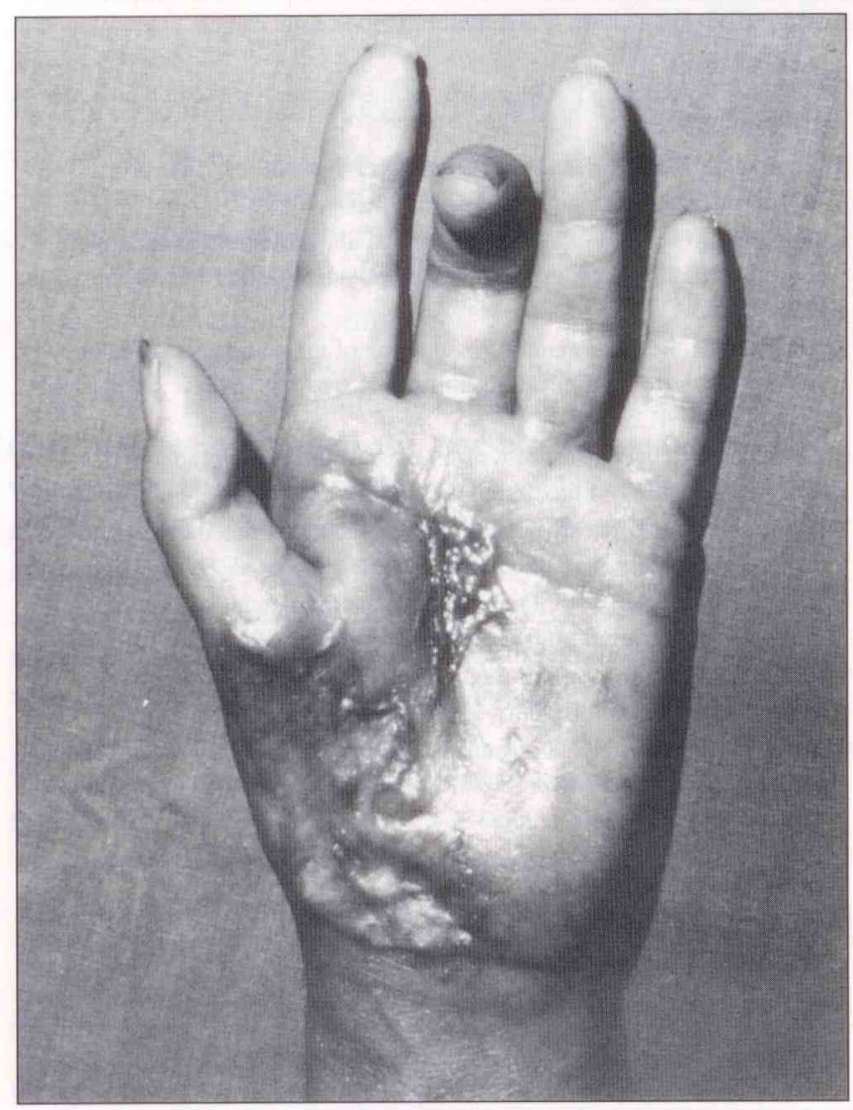

Figure 3) Case 2: Traumatic friction-avulsion of thenar muscles

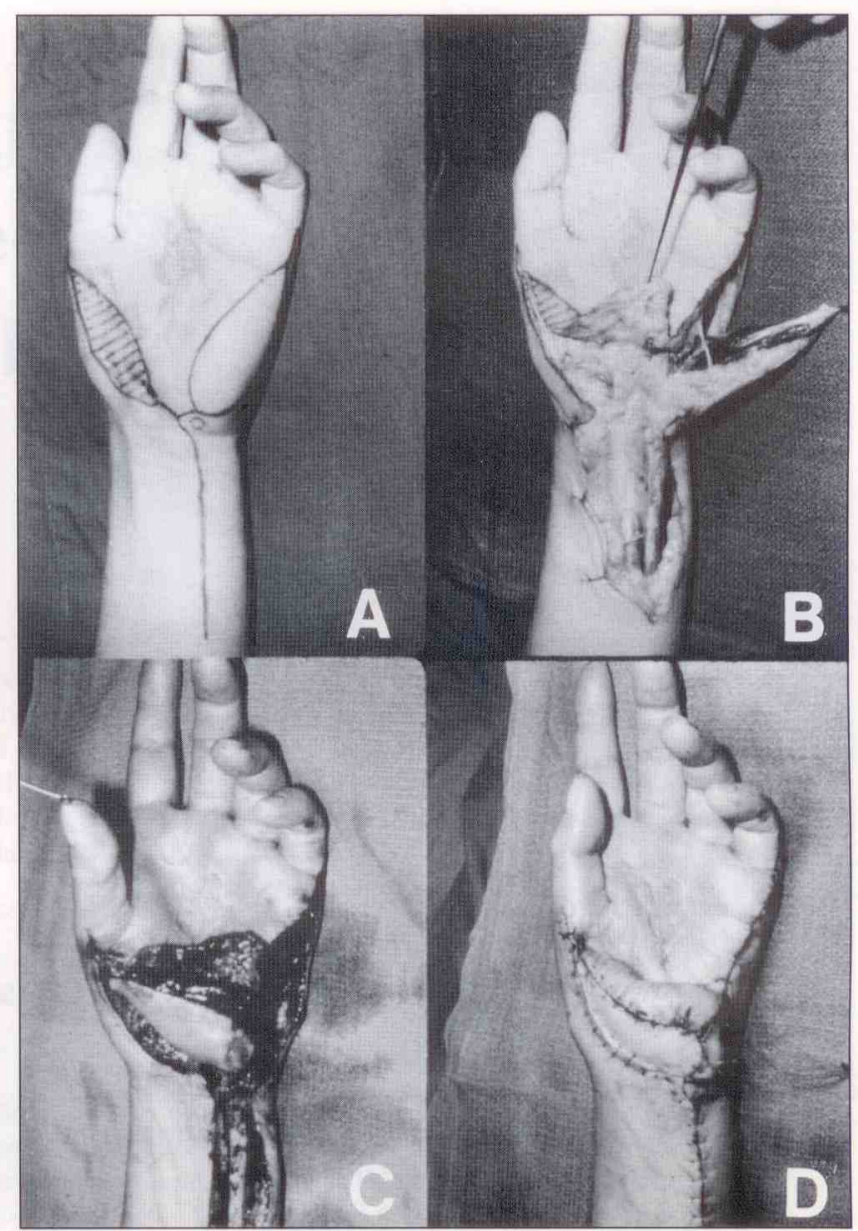

Figure 4) Case 2: A Planning the transfer. B Hypothenar myoctaneous flap ready for transfer. $C$ Transfer completed. D Final appearance at conclusion of surgery (skin graft was used)

marked thenar wasting was evident (Figure 1) and the patient was unable to oppose his thumb.

In August 1991; the patient underwent transfer of the abductor flexor digiti minimi from the hypothenar to the thenar eminence. The origin of the muscle and its neurovascular bundle were preserved. The tendons were inserted into the dorsoradial aspect of the base of the proximal phalanx (Figure 2).

\section{Case 2}

A 39-year-old female, right hand dominant, was involved in a motor vehicle accident in May 1979. She sustained a friction-avulsion of the thenar muscles of the left hand, as well as division of the flexor tendons and radial digital nerve of the left index finger.

Initial treatment in peripheral hospital achieved healing with no attempt to restore function (Figure 3).

In April 1980, following a course of intensive physiotherapy, the patient underwent reconstruction of the thenar eminence using the flexor and abductor digiti minimi as a myocutaneous flap (Figure 4). Subsequently the flexor of the index, as well as the digital nerve, were repaired. 


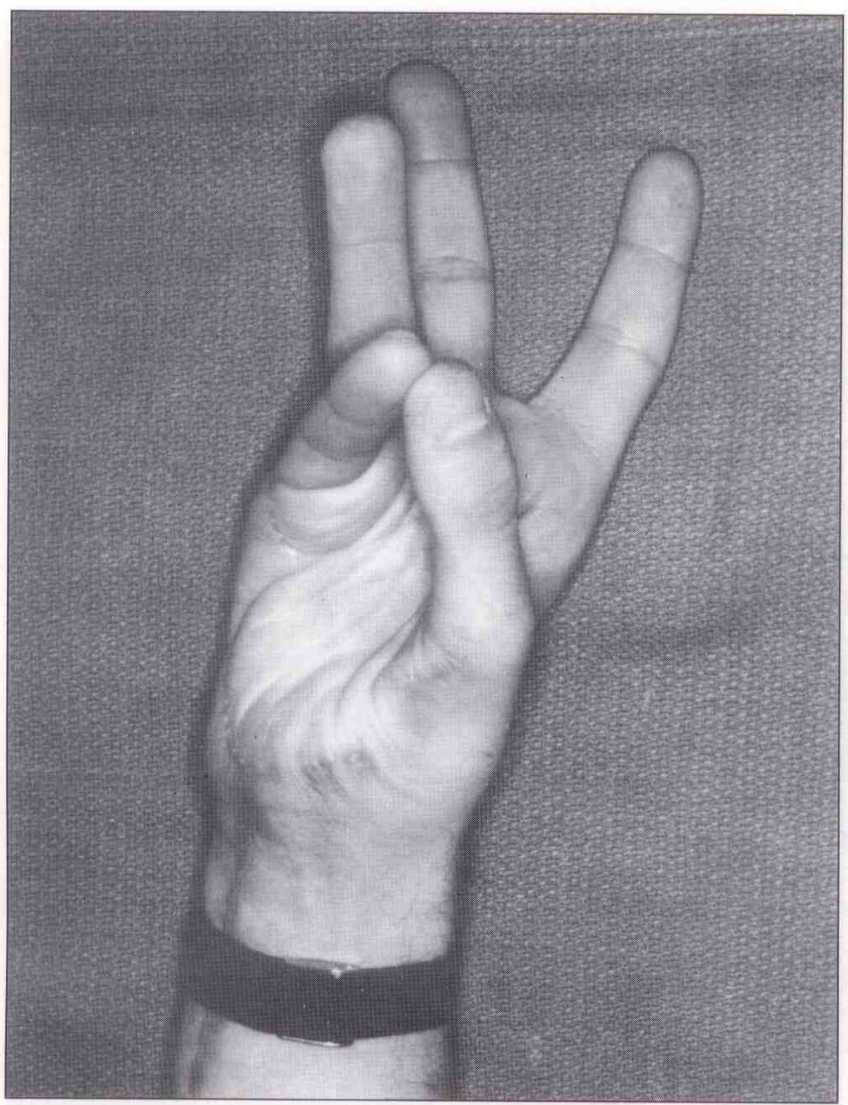

Figure 5) Case 1: Postoperatively patient is able to oppose thumb fully

\section{RESULTS}

Many methods have been used to evaluate functional recovery for opposition of the thumb. Results for these two cases are evaluated using the Wissinger and Singer (13) evaluation method, presented in Table 1. Both patients were pleased with overall outcome of the surgery.

The first patient noticed significant improvement in his ability to handle small objects (Figure 5) and the second, a typist, was able to return to her original occupation (Figure 6).

\section{DISCUSSION}

Restoration of opposition using hypothenar muscle transfer (of both abductor and flexor digit minimi) appears to have produced satisfactory results in these two patients.

The intrinsic muscle is replaced with another, which has the same amplitude and direction of contraction; thus, the need for a tendon graft is avoided. The muscles are synergistic so cortical reorientation is not required. Additionally, there is no significant loss of movement of the little finger.

The disadvantage of the Huber procedure is that it requires increased operative time since it involves a difficult dissection. This modification of the Huber transfer, using the abductor and flexor digiti minimi, affords easier dissection, as there is a natural plane of separation between the abductor and flexor digiti minimi and the deeper opponens digiti minimi with common tendon insertion.

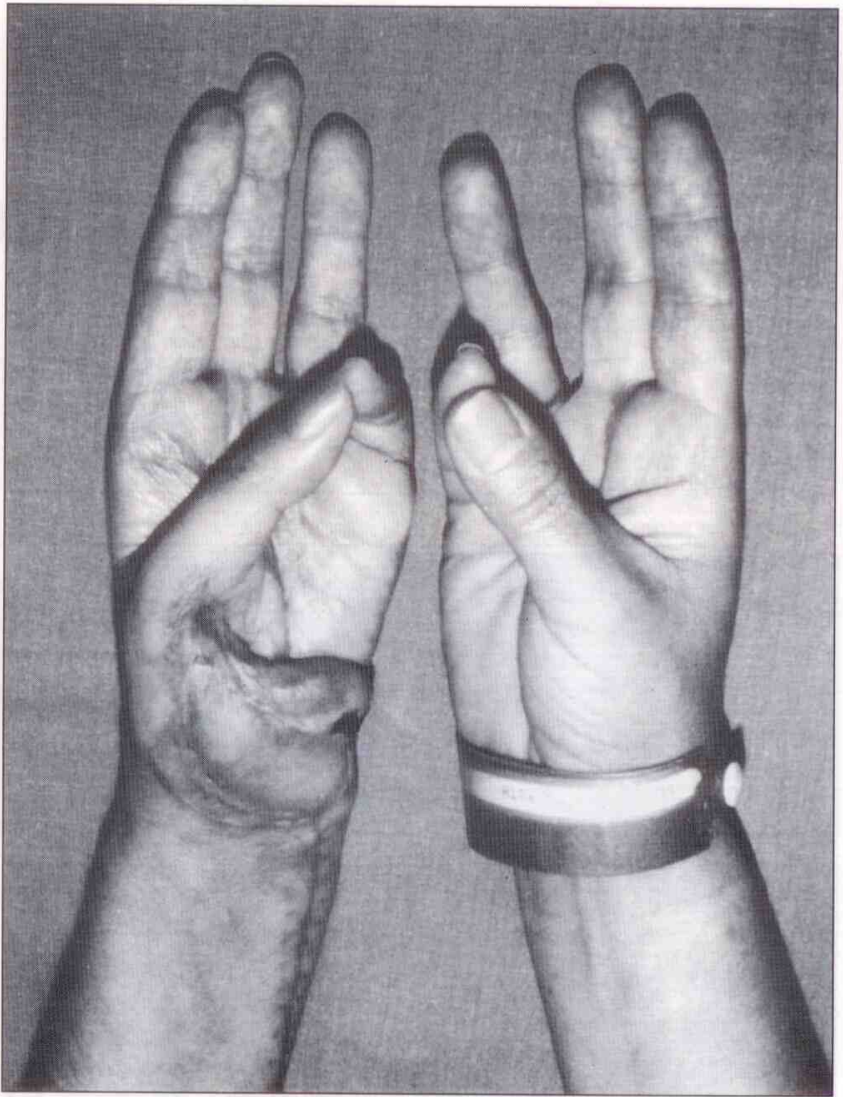

Figure 6) Case 2: Postoperatively significant improvement of opposition

\section{REFERENCES}

1. Bunnell S. Opposition of the thumb. J Bone Joint Surg 1938;20A:269-83.

2. Tubiana R, Valentin P. Opposition of the thumb. Surg Clin North Am 1968;48:967-77.

3. Burkhalter WE, Christensen RC, Brown P. Extensor indicis proprius opponensplasty. J Bone Joint Surg 1973;55A:725-32

4. Edgerton MT, Brand PW. Restoration of abduction and adduction to unstable thumb in median and ulnar paralysis. Plastic Reconst Surg 1956:36: 150-64.

5. Goldner JL. Replacement of the function of the paralyzed adductor pollicis with flexor digitorum sublimis. A ten year review. J Bone Joint Surg 1967;49A:583-4.

6. Henderson ED. Transfer of wrist extensors and brachioradialis to restore opposition of the thumb. J Bone Joint Surg 1962;44A:513-22

7. Littler JW. Tendon transfer and arthrodesis in combined median and ulnar nerve paralysis. J Bone Joint Surg 1949; 31A:225-34.

8. Littler JW, Cooley SGS. Opposition of the thumb and its restoration by abductor digiti quinti transfer. J Bone Joint Surg 1963;45A:1389-96.

9. Makin M. Translocation of flexor pollicis longus tendon to restore opposition. J Bone Joint Surg 1967;49B:459-61.

10. Phalen GS, Miller RC. The transfer of wrist extensor muscles to restore or reinforce flexion power of the fingers and opposition of the thumb. J Bone Joint Surg 1947;29:993-7.

11. Huber E. Hilfsoperation bei mediannslahmung. Deutsche Zeitschr Chir 1921;162:271-5.

12. Nicolaysen J. In Nordisk kirurgisk forening. Forhandinger Thirteenth Meeting Helsingfor, 1921;118.

13. Wissinger HA, Singer EG. Abductor digiti quintiopponensplasty. J Bone Joint Surg 1977;59A:895-8. 